\title{
Interfaces Educativas: Implicações de design e processos cognitivos do jogo Nicetown
}

\author{
Máverick André Dionísio Ferreira', Ariane Nunes Rodrigues ${ }^{1}$ \\ 'Universidade de Pernambuco, Campus Garanhuns (UPE) \\ CEP 55.294-902 - Garanhuns - PE - Brasil \\ \{amaverick70@gmail.com, ariane.rodrigues@upe.br\}
}

\begin{abstract}
The insertion of educational games in the education process and learning is a future trend that can favor the dynamism and stimulate the interest of students. The main challenge faced by educational applications is to guarantee the lucidity games through aligned interface to content. This article defends the idea that the designing education interfaces must be guided by design of implications that direct the achievement of cognitive processes. In this sense, the article presents the design process with emphasis on evolutionary prototyping of interfaces educational game Nicetown. Choose appropriate strategies and implications for cognitive processes directs effective learning when it comes to environmental awareness.
\end{abstract}

Resumo. A inserção de jogos educativos no processo de ensino e aprendizagem é uma tendência futura que pode favorecer o dinamismo e estimular o interesse dos estudantes. O principal desafio enfrentado pelas aplicações educativas está em garantir a ludicidade dos jogos via interface alinhada aos conteúdos. Este artigo defende a ideia de que a concepção das interfaces educativas deve ser guiada por implicações de design que direcionam o atingimento dos processos cognitivos. Neste sentido, o artigo apresenta o processo de design com ênfase na prototipação evolutiva das interfaces do jogo educativo Nicetown. Escolher estratégias e implicações adequadas aos processos cognitivos direciona a uma aprendizagem efetiva, quando o assunto é conscientização ambiental.

\section{Introdução}

A constante evolução da tecnologia e a crescente difusão da mesma nos diversos segmentos da sociedade atual traz à reflexão o modelo de educação contemporânea. Com isso, indagações de como tornar a escola, o ensino básico e suas respectivas disciplinas atrativas para um público cada vez mais interligado a tecnologia.

Nesse contexto emergem os softwares educativos que pontuados como capazes de desafiar e aguçar a curiosidade dos nativos digitais (SCATTONE et al, 2007), podem despertar nos educandos a motivação intrínseca para participar do processo de ensino e aprendizagem (MENEZES, 2012). No entanto, sabe-se que a utilização de softwares educativos nas salas de aula não garante o sucesso na relação aluno e conhecimento, mas pode contribuir positivamente para a aprendizagem de determinados conteúdos dependendo da qualidade do artefato e de como ele é utilizado (AGUIAR, NASCIMENTO, 2014; WELTER et al, 2014; NUNES et al, 2014).

Não como solução ou paliativo, mas ao considerar com caráter agregador no processo já existente, a inserção das TIC's no âmbito escolar, segundo Gomes (2012) 
ganhará destaque até 2017 onde as ferramentas tecnológicas farão parte do cotidiano escolar com mais frequência. Inclusive pela adoção de jogos eletrônicos educativos, pois, ao serem considerados ferramentas lúdicas podem promover uma melhor mediação no processo de ensino e aprendizagem dos conceitos trabalhados em sala de aula, nas mais diferentes áreas do conhecimento. Em meio às projeções acerca da utilização das tecnologias para fins educativos, entende-se que o desenvolvimento de aplicações para este fim requer certos cuidados, pois além de dispor no software os conteúdos propostos embasados por teorias de aprendizagem, deve-se enfatizar também as dimensões técnicas, especificamente a interface.

Neste sentido, Reategui (2007) defende o papel imprescindível da interface na interação aluno-computador e consequentemente na aprendizagem de conteúdos. $\mathrm{O}$ autor ainda destaca o grande número de aplicações educativas com deficiências nos aspectos visuais. Para ele, o aluno deverá deter esforços para o aprendizagem dos conteúdos e não para aprender a manusear o sistema, seja ele jogo eletrônico, objeto de aprendizagem entre outros, (SANTOS, TAROUCO, 2007).

A necessidade de conceber interfaces com baixo nível de complexidade remete a importância de considerar implicações de design durante a concepção da interface do software educativo para direcionar o aprendizado por meio dos processos cognitivos. Neste aspecto, Nunes e Girafa (2003) definem processos cognitivos como a maneira em que o ser humano adquire o conhecimento. Nos fundamentos da Interação Humano Computador (IHC) os processos cognitivos podem assumir diferentes processos mentais como a percepção, atenção, memória e aprendizagem e podem proporcionar formas efetivas de interação. Em um processo de design de interfaces educativas, compreender os processos essenciais da cognição permite ao designer preparar projetos mais eficientes que possam efetivamente favorecer uma melhor aprendizagem para seus usuários (PREECE, 2005).

Alinhado a este contexto, o presente artigo busca enfatizar a relevância de conceber interfaces educativas alinhadas às estratégias que direcionam ao atingimento dos processos cognitivos. Neste sentido, o artigo descreve com maiores detalhes o processo de design alinhado a técnica de prototipação evolutiva das interfaces do jogo educativo NiceTown. O jogo, que tem como foco a conscientização ambiental, adotou diferentes estratégias implicadas nas interfaces de forma que possa favorecer à reflexão e o aprendizado dos estudantes quanto ao processo de coleta seletiva e saneamento básico. Em (FERREIRA et al, 2014) pode ser compreendido todo o processo de desenvolvimento do jogo. Como diferencial, este artigo mantêm foco nas implicações de design alinhadas aos processos cognitivos integrados durante toda a evolução das interfaces do jogo.

Para tanto, organizou-se o artigo em 4 seções. A seção 2 expõe aspectos que devem ser levados em conta na concepção de interfaces educativas alinhadas a cognição dos educandos. Na seção 3 é apresentado o processo de design do jogo NiceTown, sendo descrito todo o processo de prototipação do mesmo, de modo a enfatizar as implicações de design e os processos cognitivos decorrentes da evolução dos protótipos. Por fim, a seção 4 refere-se as considerações finais.

\section{Interfaces Educativas}

A concepção de uma interface educativa condiz à necessidade de escolher estratégias cognitivas adequadas que possam impactar diretamente na aprendizagem dos conceitos associados. Sabe-se que uma interface atraente impacta positivamente na promoção da 
aprendizagem e que estes aspectos relacionam-se sobretudo à limitação da qualidade e quantidade de informações que podem ser percebidas e memorizadas. Devido ao seu caráter interdisciplinar, a área de interação humano computador considera os fundamentos da psicologia cognitiva, que como área reconhece a necessidade em postular algum nível de representação mental, ao considerar os processos de aprendizagem e de aquisição de conhecimento.

Segundo Preece (2005), a necessidade de compreender os processos associados à cognição é relevante ao processo de concepção das interfaces, visto que é papel do designer preparar projetos eficientes para que de fato a aprendizagem dos usuários seja efetiva. $\mathrm{O}$ designer deve considerar princípios e diretrizes adequadas a cada situação acerca do domínio do problema, dos usuários e das suas atividades. A Tabela 1 apresenta alguns tipos de processos cognitivos e suas descrições, além de implicações do design associados que, uma vez adotadas podem facilitar seu atingimento.

Tabela 1. Processos cognitivos segundo Preece (2005)

\begin{tabular}{|c|l|l|}
\hline $\begin{array}{c}\text { Processos } \\
\text { Cognitivos }\end{array}$ & \multicolumn{1}{|c|}{ Descrição } & \multicolumn{1}{|c|}{ Implicações de Design } \\
\hline Atenção & $\begin{array}{l}\text { Consiste no processo de selecionar } \\
\text { coisas em que se concentrar, num } \\
\text { certo momento, dentre a variedade de } \\
\text { possibilidades disponíveis. }\end{array}$ & $\begin{array}{l}\text { Fazer a informação ficar visível quando for } \\
\text { necessário, evitar inserir grande quantidade de } \\
\text { informações na interface e buscar inserir } \\
\text { imagens, gráficos etc. }\end{array}$ \\
\hline Percepção & $\begin{array}{l}\text { Refere-se como a informação é } \\
\text { adquirida do ambiente pelos } \\
\text { diferentes órgãos sensitivos. }\end{array}$ & $\begin{array}{l}\text { Utilizar ícones que possibilitem ao usuário } \\
\text { descobrir rapidamente seu significado, usar } \\
\text { sons claros e usar textos legíveis. }\end{array}$ \\
\hline Memória & $\begin{array}{l}\text { Implica recordar vários tipos de } \\
\text { conhecimentos que nos permite agir } \\
\text { adequadamente. }\end{array}$ & $\begin{array}{l}\text { Inserir funcionalidades que possibilitem aos } \\
\text { usuários determinada } \\
\text { funcionalidade sem esforços. }\end{array}$ \\
\hline Aprendizagem & $\begin{array}{l}\text { Refere-se o quão fácil é aprender a a } \\
\text { manusear o sistema. }\end{array}$ & $\begin{array}{l}\text { Criar interfaces que incentivem a exploração, } \\
\text { além de restringir as opções de modo guiar os } \\
\text { usuários na seleção das ações mais adequadas. }\end{array}$ \\
\hline
\end{tabular}

$\mathrm{Na}$ literatura diversos estudos apresentam teorias que enfatizam a importância dos processos cognitivos em interfaces de softwares educativos. Em Santos e Tarouco (2007) é discutida a importância da teoria da carga cognitiva que consiste em princípios que visam o desenvolvimento/escolha de ambientes de aprendizagem alinhados à cognição humana.

Com base neste estudo fica evidente as limitações do ser humano para processar grandes quantidades de informações de modo a gerar conhecimento. Tal limitação caracteriza um anseio por interfaces que evitem sobrecarregar a cognição do educandos, ou seja, interface com uma quantidade excessiva de elementos visuais. Segundo os autores o número mágico " $7 \pm 2$ " refere-se a capacidade humana de processar de 5 a 9 informações com comodidade. Com isso para desenvolver aplicações educativas devese levar em consideração os três principais tipos de carga cognitiva, são elas: (1) carga cognitiva intrínseca referente à complexidade do conteúdo proposto, (2) carga cognitiva natural relativa às atividades que potencializam a aprendizagem e a (3) carga cognitiva externa que são fatores que remetem à sobrecarga cognitiva e prejudicam a aprendizagem. Segundo a teoria, na concepção de interfaces educativas, deve-se controlar a carga cognitiva intrínseca, elevar ao máximo a carga natural e reduzir ao máximo à externa.

Por fim, Reategui (2007) destaca que uma interface educativa atraente, ou seja, contextualizada com o cognitivo do aluno, repercutirá positivamente na usabilidade da 
aplicação e em consequência na aprendizagem dos conceitos propostos. $\mathrm{O}$ autor expõe características desejáveis na modalidade de aplicação em questão, tais como utilização de textos em conjunto com imagens para promover à associação de conceitos, organização das informações na tela seguindo a engenharia da usabilidade, inserção de figuras com efeitos e funções adequadas, aspectos de interação, dentre outras.

Enxerga-se que os trabalhos aqui relacionados representam apenas um fragmento da imensa literatura, no entanto, suficiente para trazer a discussão os aspectos e importância da interface educativa para o processo de ensino e aprendizagem mediado por computador. Diante disso, o presente artigo busca evidenciar a presença de conceitos associados à área de IHC e da psicologia cognitiva durante todo o processo de prototipação de um jogo eletrônico educativo, de modo a guiar a aprendizagem acerca da educação ambiental por meio de atingimento dos processos cognitivos humanos.

\section{Processo de Design do jogo NiceTown}

O jogo eletrônico educativo NiceTown foi desenvolvido durante a disciplina de estágio supervisionado III no curso de Licenciatura em Computação da Universidade de Pernambuco do Campus Garanhuns. Este processo considerou a integração das atividades das áreas de Interação Humano Computador (IHC) com a Engenharia de Software. Neste sentido, os processos de IHC foram definidos paralelamente e incorporados aos processos de engenharia.

Antes de descrever as atividades associadas ao processo de concepção, considera-se importante ressaltar que o jogo Nicetwon tem como domínio à Educação Ambiental. Seu objetivo pedagógico central consiste em conscientizar estudantes acerca da importância da preservação do meio ambiente através de atitudes sustentáveis. Os principais conteúdos associados referem-se ao processo de coleta seletiva e saneamento básico. A ideia do jogo é simular uma cidade fictícia onde problemas ambientais são apresentados. O desafio do estudante consiste justamente em tomar decisões adequadas conforme as situações e com o apoio do nível de satisfação da população, que compõe os níveis de saneamento e lixo. O estudante precisa manter o nível de satisfação da população sob estes dois aspectos.

Para o desenvolvimento considerou-se o processo iterativo e incremental pela possibilidade em se definir entregas gradativas do produto (SOMMERVILLE, 2007). Alinhado a este, o modelo simples de processo de design que é composto de quatro atividades principais foi adotado (i) identificar as necessidades e requisitos; ii) (re)design; iii) construir uma versão interativa e iv) avaliar).

Esta seção destaca sobretudo o processo de design ((re)design) das interfaces do jogo, alinhando as implicações de design aos processos cognitivos e apoiado pela técnica de prototipação evolutiva. De acordo com Preece (2005) esta técnica consiste em fazer os protótipos evoluírem de modo a tornarem-se o produto final.

Por se tratar de um produto com fins educativos, um docente com formação em Ciências Naturais foi envolvido no processo de concepção para contribuir pedagogicamente na estruturação das estratégias de ensino sobre os conceitos ambientais. Durante o processo de prototipação, as três etapas consideradas referem-se a definição de requisitos, prototipação e avaliação. No processo de avaliação dos protótipos, potenciais usuários reais eram selecionados pelo docente para jogar mediante observação dos integrantes da equipe de desenvolvimento. Não foi estipulado tempo para interação visto que eles deveriam explorar ao máximo o jogo para informar suas percepções neste processo. Após as interações, entrevistas informais eram 
realizadas pelos membros, visando coletar informações acerca dos erros ("Você identificou algum erro no jogo?"), dificuldades associadas pela realização das atividades ("Você teve dificuldade para executar alguma atividade proposta?") e propostas de melhorias ("Quais dicas você poderia dar para melhorar o jogo?"). As anotações realizadas pelos integrantes serviam de base para as discussões que aconteciam durante as reuniões com os professores orientadores da disciplina. É importante destacar que tais etapas foram repetidas durante toda a evolução dos protótipos gerados.

$\mathrm{Na}$ fase de definição dos requisitos, a equipe de desenvolvimento discutia e analisava juntamente com o docente da área os incrementos do jogo. Com base nas discussões, consideravam-se as necessidades e dificuldades de aprendizagem dos estudantes no contexto do jogo e assim os requisitos funcionais e não funcionais foram definidos. Após definidas as metas iniciava-se o processo de prototipação alinhada ao desenvolvimento. Para tal, foram utilizados dois programas, o CorelDraw (Versão de avaliação) para criar os cenários e personagens e o GameMaker 8.1 para programar as funcionalidades do jogo. Vale ressaltar que embora o GameMaker possibilite criar jogos em 2D e simula ambientes 3D, o jogo NiceTown é todo desenvolvido em 2D.

\subsection{Prototipação Evolutiva alinhada aos processos cognitivos}

Nesta seção serão exibidos em ordem cronológica do projeto os protótipos que foram gerados durante a concepção do jogo e sua correlação as implicações de design adotadas como estratégias a atingir os processos cognitivos. O primeiro protótipo exibido na Figura 1 apresenta um cenário que simula uma cidade, tal escolha é embasada pela teoria de aprendizagem significativa de Ausubel (1982) a qual defende a importância de levar em conta os conhecimentos prévios dos alunos durante o processo de ensino e aprendizagem. Com base nessa teoria acredita-se que colocando o jogador em um cenário que represente uma cidade (seu cotidiano) a aprendizagem dos conteúdos será potencializada.

O primeiro protótipo, como representa a Figura 1, ainda se encontra em um estágio bem inicial sendo difícil a sua associação com uma cidade conforme destacou alguns alunos ao participarem do processo de avaliação desta versão. Portanto, nesta fase os cenários ainda se encontram em um estágio com poucas implicações associadas a processos cognitivos.

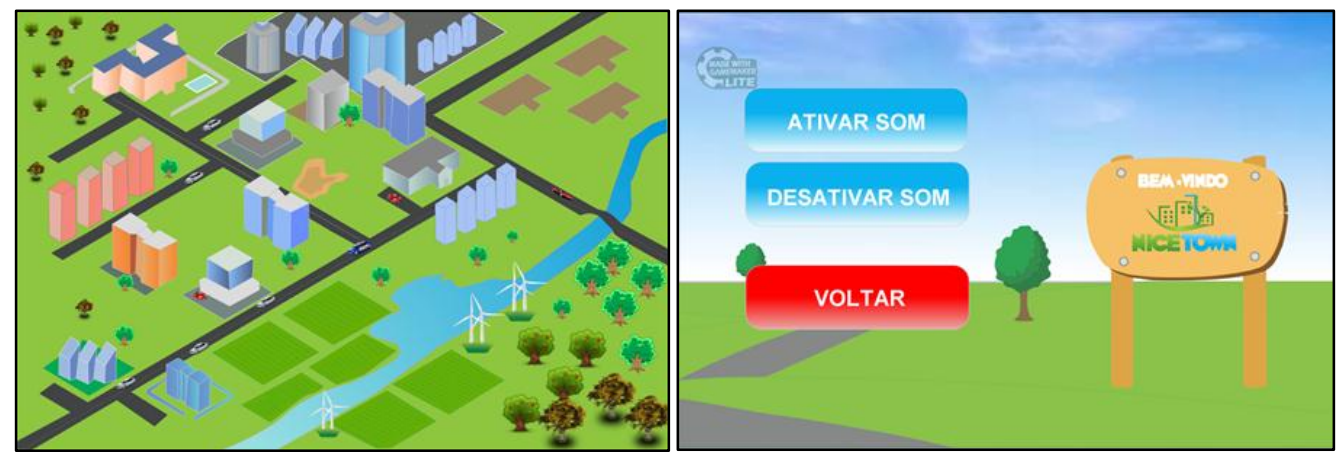

Figura 1. Protótipos iniciais do jogo

A partir das críticas relacionadas à interface traçou-se como uma das metas melhorar a iconização do cenário. Além disso, adicionar um painel com previsão do tempo, nível de lixo e o nível de satisfação da população. A ideia com a inclusão da previsão do tempo e dos níveis referem-se a possibilidade do jogador de refletir sobre as 
atuais condições meteorológicas e ambientais da cidade, para através disso tomar decisões estratégicas. Pode-se tomar como exemplo a situação de chuva, onde o aluno ao verificar a previsão precisará recolher o máximo de lixo possível, evitando assim, que a cidade NiceTown seja inundada por conta de entupimento dos bueiros.

A Figura 2 mostra que os requisitos projetados para esta versão foram atendidos, tendo como marco demonstrações de entusiasmo por parte dos alunos com as melhorias realizadas no jogo. Porém, houve um questionamento que chamou a atenção da equipe de desenvolvimento com relação ao personagem do jogo. Foi questionado o porquê de só existir a possibilidade de jogar com o personagem "chiquinho", nome este escolhido em homenagem ao patrono do meio ambiente Chico Mendes.

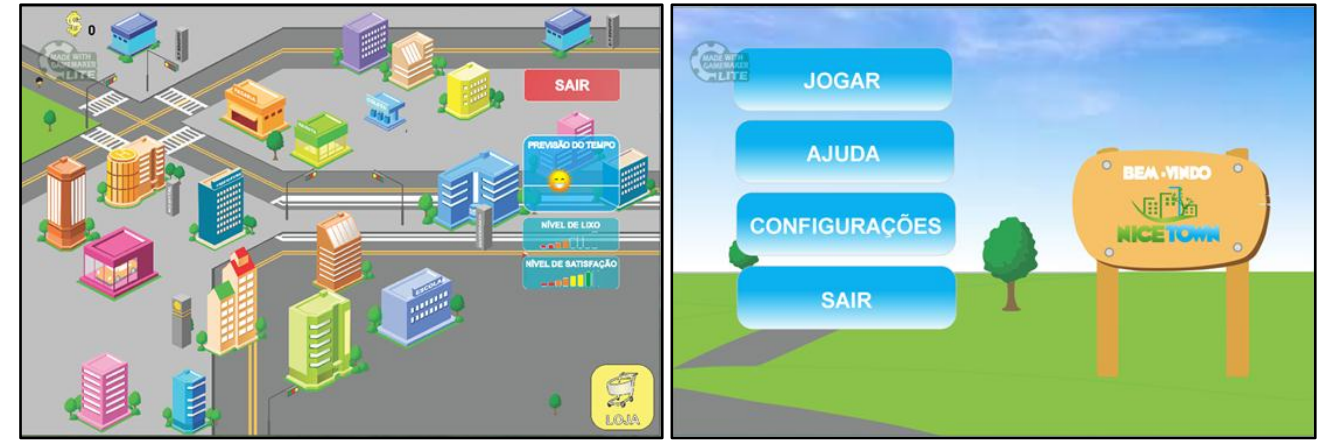

Figura 2. Protótipos intermediários

Com a necessidade de representar as condições climáticas, a estratégia adotada foi a de utilizar signos. Em IHC, um signo refere-se ao processo de representação de um objeto que estimula o interpretante, ou seja, o interpretante é a significação de um conceito vinculado pelo signo. Esse processo de reconhecimento (signo para com o objeto) acontece através de uma relação triádica envolvendo o signo, o objeto que o signo representa e o interpretante (PUGA, FERREIRA, 2007). Esse processo de significação e sua representação para a aprendizagem no jogo é exibida na Tabela 2.

Tabela 2. Implicações de design referentes aos protótipos intermediários 1

\begin{tabular}{|c|c|l|}
\hline \multicolumn{1}{|c|}{ Implicações de design } & Processo Cognitivo & \multicolumn{1}{|c|}{ Impacto na Aprendizagem } \\
\hline Inserir um signo referente ao Sol & Percepção & $\begin{array}{l}\text { Promove a associação da imagem } \\
\text { representativa do sol ao clima de estiagem } \\
\text { (dia de sol) e por consequência repercute } \\
\text { em tomadas de decisões convenientes ao } \\
\text { momento. }\end{array}$ \\
\hline $\begin{array}{l}\text { Inserir um signo referente às } \\
\text { nuvens }\end{array}$ & Percepção & $\begin{array}{l}\text { Promove a associação da imagem } \\
\text { representativa da nuvem à possibilidade de } \\
\text { chuva eminente (dia de chuva) por } \\
\text { consequência resulta em decisões pontuais. }\end{array}$ \\
\hline
\end{tabular}

Após reunião com os professores orientadores da disciplina de estágio novas metas foram traçadas. Possibilitar a escolha do personagem foi listado dentre os objetivos, bem como a criação do nível de saneamento básico que junto com o nível de lixo passam a compor o nível de satisfação da população. Tal modificação é motivada pela importância de diminuir a quantidade de informações na tela, evitando assim a sobrecarga cognitiva. Busca-se com essa ação também melhorar a percepção dos alunos acerca da atual situação da cidade para facilitar a tomada de decisões, como mostra a Figura 3. 


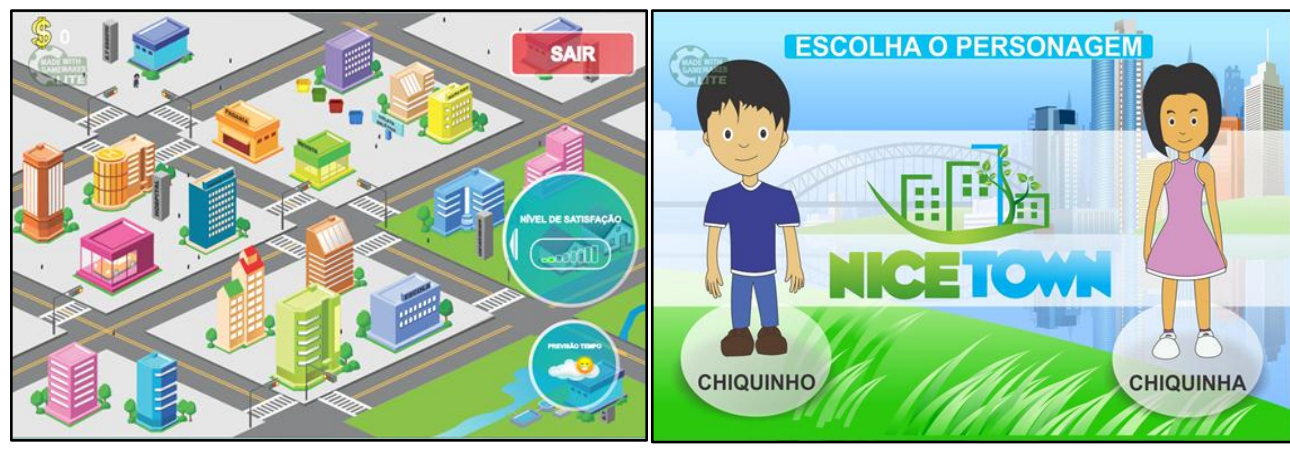

Figura 3. Protótipos intermediários

Ao fazer uma análise geral dos protótipos representados pela Figura 3 é possível perceber melhorias significativas nos aspectos visuais, tanto nos prédios quanto nos níveis. Outro avanço refere-se a possibilidade do jogador interagir com alguns pontos da cidade, como a prefeitura, escola, revista, mercado e padaria. Cada ambiente desse possibilita ao aluno comunicar-se com figuras da sociedade, por exemplo, na prefeitura o jogador é recebido pelo prefeito que busca passar informações atuais da cidade. $\mathrm{Na}$ escola de NiceTown uma professora explica os conteúdos relacionados a saneamento básico e coleta seletiva.

Apesar das melhorias visíveis nesse fragmento do jogo, percebeu-se certa resistência dos jogadores em notar mudanças no nível de satisfação da população e da previsão do tempo. Essa conclusão se baseia nas decisões incoerentes para com o momento de tomadas de decisão pelos alunos, bem como em frases proferidas durante o teste, como: "Eu não tinha percebido que o nível de lixo estava tão ruim".

As funcionalidades incrementadas na versão exibida na Figura 3 apontam para implicações de design com o objetivo de possibilitar o atingimento de alguns processos cognitivos conforme exibe as Tabelas $3 \mathrm{a}$ e $3 \mathrm{~b}$.

Tabela 3a. Implicações de design referente aos protótipos intermediários 2

\begin{tabular}{|c|c|c|}
\hline Implicações de design & Processo Cognitivo & Impacto na Aprendizagem \\
\hline Definir as cores das lixeiras & Percepção & $\begin{array}{l}\text { Favorece a associação das cores das lixeiras } \\
\text { aos respectivos tipos de lixo que podem ser } \\
\text { depositados. Sendo possível depositar na } \\
\text { lixeira vermelha objetos de plástico, na } \\
\text { lixeira verde objetos de vidro, na lixeira } \\
\text { azul objetos de papel e na lixeira amarela } \\
\text { objetos de metal. }\end{array}$ \\
\hline $\begin{array}{l}\text { Definir efeito sonoro decorrente } \\
\text { a tentativa de realizar o depósito } \\
\text { do lixo na lixeira } \\
\text { correta/incorreta }\end{array}$ & Atenção & $\begin{array}{l}\text { Possibilita a associação das cores das } \\
\text { lixeiras aos respectivos tipos de lixo que } \\
\text { podem ser depositados em cada lixeira a } \\
\text { partir do acerto/erro. No momento do } \\
\text { acerto, por exemplo, é emitido um som de } \\
\text { dinheiro indicando que o jogador ganhou } \\
\text { uma quantia a qual poderá ser usada para } \\
\text { adquirir itens para ajudá-lo em suas tarefas. }\end{array}$ \\
\hline
\end{tabular}


Tabela 3b. Implicações de design referente aos protótipos intermediários 2

\begin{tabular}{|l|l|l|}
\hline \multicolumn{1}{|c|}{ Implicações de design } & Processo Cognitivo & \multicolumn{1}{|c|}{ Impacto na Aprendizagem } \\
\hline $\begin{array}{l}\text { Colocar mensagem alertando } \\
\text { mudança na previsão do tempo }\end{array}$ & Atenção & $\begin{array}{l}\text { Coopera para tomada de decisão dos } \\
\text { jogadores, pois, no momento em que } \\
\text { ocorrem mudanças na previsão do tempo é } \\
\text { emitida uma mensagem chamando a } \\
\text { atenção do jogador. }\end{array}$ \\
\hline $\begin{array}{l}\text { Colocar mensagem que indica o } \\
\text { fim do estágio de coleta seletiva }\end{array}$ & Atenção & $\begin{array}{l}\text { Facilita a aprendizagem acerca dos tipos de } \\
\text { materiais que podem ser produzidos a partir } \\
\text { da reciclagem. Quando o estágio de coleta } \\
\text { seletiva é finalizado, surge um alerta com } \\
\text { um exemplo de material reciclado. }\end{array}$ \\
\hline
\end{tabular}

$\mathrm{Na}$ versão final dos protótipos, exibida na Figura 4, é possível identificar a criação da tela de ajuda para possibilitar o aluno ao tirar dúvidas sobre as funcionalidades do jogo. Funcionalidade muito importante em um software, pois segundo Nielsen (1993) o manual é parte essencial para uma aplicação. Outra modificação foi a mudança de posicionamento dos níveis e da previsão do tempo, sendo alocados do lado direito da tela. Essa mudança foi motivada pela dificuldade dos jogadores em notar alterações que viessem a ocorrer na cidade. Além disso, levou em consideração de que o modelo de leitura do mundo ocidental é realizado no sentido da esquerda para direita (REATEGUI, 2007). A estratégia de modificar o posicionamento do níveis e da previsão do tempo facilitou a tomada de decisão pelos alunos durante sua interação. Também foi acrescentado o botão de configurações localizado na parte superior do lado direito da tela cuja função é ativar e/ou desativar o som e voltar para o menu principal.
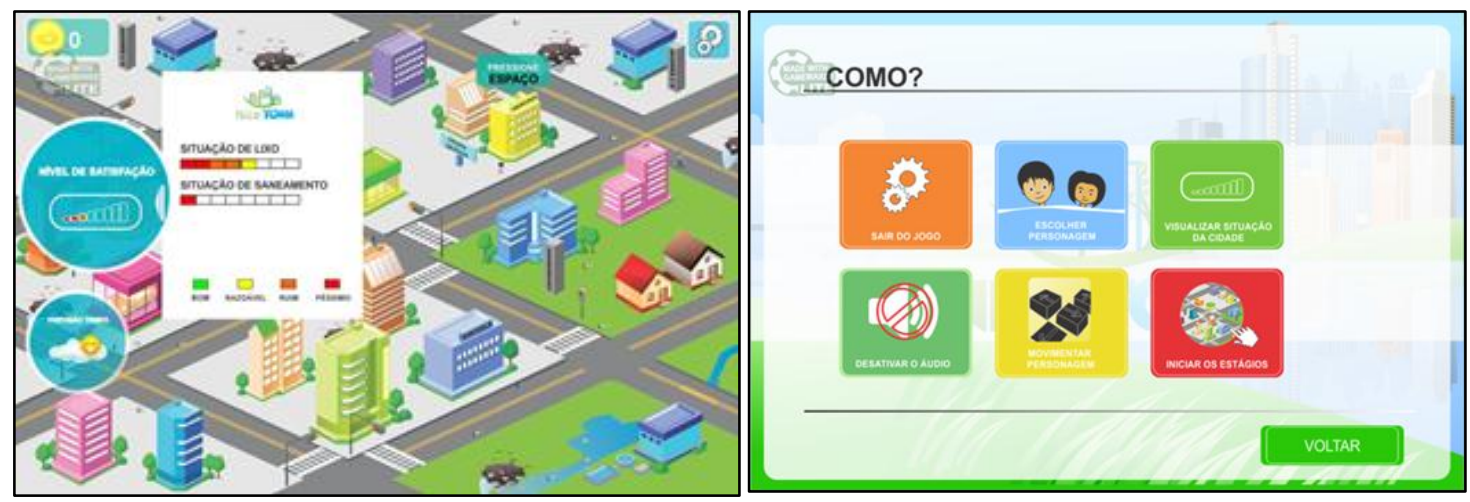

Figura 4. Protótipos finais (visão geral)

Ainda na Figura 4 pode-se perceber a inserção de buracos na cidade para evidenciar aos jogadores a ausência de saneamento, indagando, com isso, a necessidade de montar redes de esgotos. A montagem acontece com a ida do personagem a uma das três estações de tratamento existentes na cidade NiceTown. Ao chegar na estação de tratamento o jogador terá que montar a passagem de esgoto a qual segue o conceito de quebra-cabeça e se torna mais complexa a cada estação visitada. A Figura 5 mostra o primeiro nível de complexidade antes de ser montado e após. 


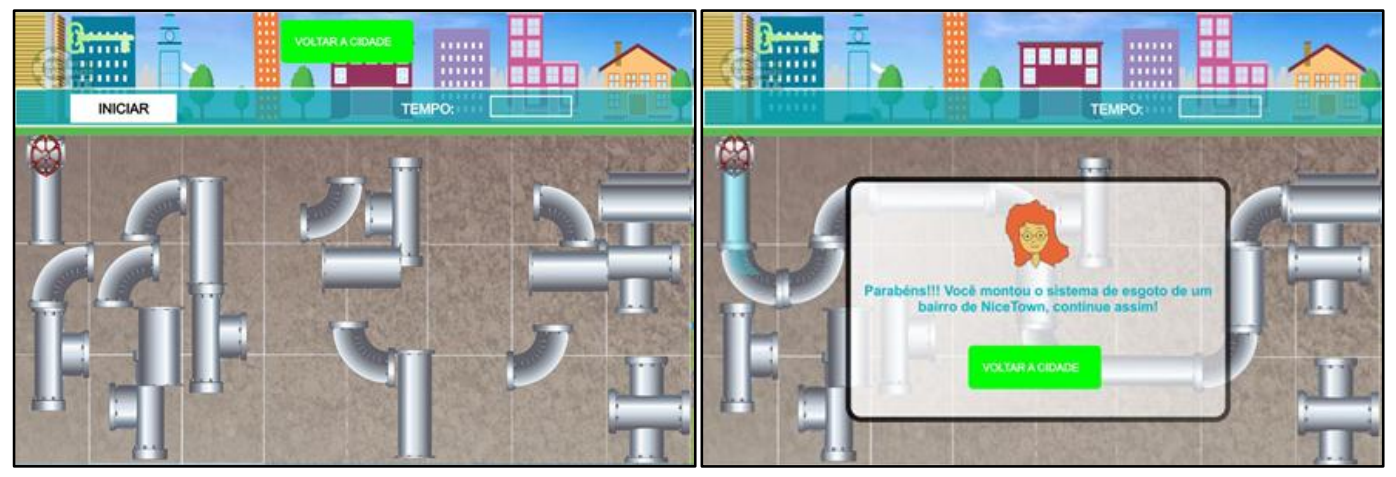

Figura 5. Protótipos finais (estágio saneamento básico)

As funcionalidades acrescentadas na versão final do jogo possibilitam o atingimento de alguns processos cognitivos, estes são sintetizados na Tabela 4.

Tabela 4. Implicações de design referente aos protótipos finais

\begin{tabular}{|l|c|l|}
\hline \multicolumn{1}{|c|}{ Implicações de Design } & Processos Cognitivos & \multicolumn{1}{c|}{ Impacto na Aprendizagem } \\
\hline $\begin{array}{l}\text { Inserir signos nos botões de } \\
\text { ajuda }\end{array}$ & Percepção & $\begin{array}{l}\text { Facilitar o entendimento sobre as opções da } \\
\text { tela de ajuda e com isso, aumentar as chances } \\
\text { do usuário obter êxito em suas ações no jogo. }\end{array}$ \\
\hline $\begin{array}{l}\text { Mostrar informes nos } \\
\text { prédios que possibilitam } \\
\text { interação }\end{array}$ & Memória & $\begin{array}{l}\text { Auxiliar no reconhecimento dos prédios que } \\
\text { permitem interação e como interagir com os } \\
\text { mesmos. }\end{array}$ \\
\hline
\end{tabular}

A partir dos protótipos gerados nota-se que a interface do jogo eletrônico educativo NiceTown possui diversas implicações de design com o objetivo de atingir processos cognitivos. A avaliação do protótipo final ficou marcada pelos feedbacks positivos dos alunos, uma vez que, todos conseguiram realizar as tarefas propostas no jogo com bastante facilidade.

\section{Considerações finais}

A escola passa por um momento de mudança frente à nova maneira de ensinar e aprender. $\mathrm{O}$ uso de dispositivos tecnológicos quebram barreiras físicas e tornam o acesso a informação divertido, dinâmico e a qualquer hora/lugar. Neste contexto, a escola ao buscar adequação a uma realidade tecnológica vivenciada pelos nativos digitais, busca gradativamente alinhar o ensino e a tecnologia a fim de tornar as aulas mais atraentes e motivadoras. No entanto, a maioria das aplicações educativas disponíveis são descontextualizadas dos processos cognitivos dos alunos. Em meio a esse panorama, o presente artigo descreveu o processo de design alinhado a técnica de prototipação do jogo eletrônico educativo NiceTown, buscando analisar as implicações de design e os processos cognitivos decorrentes dessas implicações em cada protótipo gerado.

Com isso, foi possível notar que o jogo NiceTown possui em sua interface diversas implicações de design com foco em atingimento de processos cognitivos, sendo atribuído ao processo de design e a prototipação evolutiva. Acredita-se ainda que o envolvimento dos potenciais usuários reais no processo de desenvolvimento do software educativo ao testar e opinar foi extremamente importante. Essa conclusão é justificada pelo grande número de mudanças que surgiram ao longo do processo em função dos feedbacks disponibilizados pelos alunos a cada interação. Espera-se que mais aplicações sejam desenvolvidas com um enfoque em processos cognitivos. Como 
trabalhos futuros projeta-se avaliar paralelamente as dimensões pedagógicas e técnicas do jogo em escolas da região.

\section{Referências}

Aguiar, M. O., Nascimento, E. L. (2014) Tecnologia a favor da Educação: Um Estudo de Caso das Escolas do Espírito Santo. In: Anais XX Workshop de Informática na Escola (WIE), pág 492-501.

Ausubel, D. P. (1982) A aprendizagem significativa: a teoria de David Ausubel. São Paulo: Moraes.

Ferreira, M. A. F., Santos, H. M., Oliveira, E., Lucena, A. M. (2014) NiceTown - Um jogo Eletrônico para Ensino da Educação Ambiental. In: Anais XX Workshop de Informática na Escola (WIE), pág 298-307.

Gomes, P. (2012) As 12 tendências da educação brasileira até 2017. Disponível em: $<$ http://porvir.org/porpensar/12-tendencias-da-educacao-brasileira-ate2017/20121123>. Acesso em: 16 de Julho de 2015.

Menezes, N. C. A. P. (2012) Motivação de alunos com e sem utilização das TIC em sala de aula. Dissertação (Mestrado). Universidade Portucalense Infante D. Henrique, Porto -Portugal.

Nielsen, J. (1993) Engenharia de Usabilidade. San Francisco: Morgan Kaufmann.

Nunes, F. B., et al. (2014) Um estudo de caso sobre a importância do uso de objetos de aprendizagem no ensino fundamental como apoio pedagógico. In: Anais XX Workshop de Informática na Escola (WIE), pág 542-551.

Nunes, M., Girafa, L. (2003) A educação na ecologia digital. PPGCC/ FACIN, PUCRS.

Puga, S., Ferreira, M, M. G. V. (2007) Uma Intersecção entre a semiótica e as Inteligências Múltiplas para Construção de Sistemas Hipermídia Adaptativos para Educação Baseada na Web. In: Anais XVIII Simpósio Brasileiro de Informática na Educação - SBIE - Mackenzie, pág. 243-250.

Preece, Jennifer., Rogers, Yvonne., Sharp, Helen. (2005) Design de interação : além da interação homem-computador, Bookman.

Reategui, E. (2007) Interfaces para softwares educativos. Revista Novas Tecnologias na Educação, v.5, n.1, pág. 1-10.

Santos, L. M. A., Tarouco, L. M. R. (2007) A importância do estudo da teoria da carga cognitiva em uma educação tecnológica, Revista Novas Tecnologias na Educação, v.5, n.1, pág. 1-9.

Scattone, C.; Masini, E. F. S. (2007) O software educativo no processo de ensinoaprendizagem: Um estudo de opinião de alunos de uma quarta série do ensino fundamental. Revista Psicopedagogia, v. 24, n. 75, pág. 240-250.

Sommerville, I. (2007) Engenharia de software. $8^{a}$ ed. São Paulo: Pearson AddisonWesley.

Welter, E. F. A., Zaina, L. A. M., Leles, A. D., Ribeiro, M. S. (2014) Aprendendo História através de Museus Virtuais: uma parceria entre Professores e Museólogos. In: Anais XX Workshop de Informática na Escola (WIE), pág 76-85. 